\title{
Bilingualism, monoliteracy, and third language writing: A case from Turkish-Persian context in Iran
}

\author{
Fatemeh Poorebrahim $^{*}$, Mohammad Afsharrad ${ }^{2}$, and Behzad Ghonsooly ${ }^{3}$ \\ ${ }^{1}$ English Language Teaching Department, University of Maragheh, Maragheh, Iran \\ ${ }^{2,3}$ Department of English Language and Literature, Faculty of Letters and Humanities, Mashhad, Iran
}

\begin{abstract}
Studies on third language (L3) acquisition have shown that biliteracy has a facilitative effect on L3 writing. By comparing performances of bilinguals and monolinguals in subsequent language (English) writing, this study attempts to find whether being bilingual but not biliterate is of help to L3 writing. To this end, 52 Turk-Fars bilingual and 57 Fars monolingual females participated in the study. Data were collected through the participants' compositions and think-aloud protocols. A series of Mann Whitney $U$ tests were employed to compare the groups' total writing scores and scores in different components of writing. The results of the study revealed that bilinguals performed better than monolinguals in total writing, organization, and mechanics. However, there was no significant difference between the two groups in content, discourse, syntax, and vocabulary of their compositions. This indicates that being bilingual without necessarily being biliterate is of help to L3 writing. Moreover, it was found that English language was the most frequently used medium of thought while writing in English. The findings of this study indicate the need for developing localized bilingual education systems so that bilinguals can take maximum advantage of their background languages in the process of L3 learning.
\end{abstract}

Keywords: Bilingualism; third language (L3); writing components

\begin{tabular}{|c|c|c|}
\hline $\begin{array}{l}\text { First Received: } \\
27 \text { February } 2020 \\
\text { Final Proof Received: } \\
\text { 26 September } 2020\end{array}$ & $\begin{array}{c}\text { Revised: } \\
24 \text { May } 2020\end{array}$ & $\begin{array}{l}\text { Accepted: } \\
\text { 27 July 2020 } \\
\text { Published: } \\
\text { 31 September 2020 }\end{array}$ \\
\hline \multicolumn{3}{|c|}{$\begin{array}{l}\text { How to cite (in APA style): } \\
\text { Poorebrahim, F., Afsharrad, M., \& Ghonsooly, B. (2020). Bilingualism, monoliteracy, and third } \\
\text { language writing: A case from Turkish-Persian context in Iran. Indonesian Journal of } \\
\text { Applied Linguistics, } 10(2), 369-381 . \text { https://doi.org/10.17509/ijal.v10i2.28608 }\end{array}$} \\
\hline
\end{tabular}

\section{INTRODUCTION}

Writing is a multi-functional skill which is used to accomplish a variety of purposes. "People use writing to create imagined worlds, tell stories, share information, explore who they are, combat loneliness, and chronicle their experiences" (Graham, Gillespie, \& McKeown, 2013, p. 3). It is also essential for and has a profound effect on learning (Bangert-Drowns, Hurley, \& Wilkinson, 2004; Graham \& Perrin, 2007); we use writing for the purpose of gathering, maintaining, and transferring information. It also makes reviewing and evaluating ideas possible and is indispensable to succeed academically. In addition, it may help improve other language skills (e.g. see Graham \& Hebert, 2010, 2011).
One of the factors which may exert influence on learning different skills of additional languages including writing is the number of languages the learner already knows. The literature on bilingualism suggests a general advantage in favor of bilinguals (Afsharrad \& Sadeghi Benis, 2017; Keshavarz \& Astaneh, 2004; Keshavarz \& Ghamoushi, 2014; Modirkhamene, 2006, to name just a few). Superiority of bilinguals, as compared to monolinguals, in learning additional languages is usually accounted for by their language learning experience. When learning an L3, bilinguals have more language experience and rely on two linguistic systems and also benefit from the general effects of bilingualism (Cenoz, 2003; Herdina \& Jessner, 2002). Second language (L2) learners, on the other

\footnotetext{
* Corresponding Author

Email: poorebrahim@maragheh.ac.ir
} 
hand, have only their mother tongues to draw on and first language (L1) learners have no previouslyknown language base to benefit from in the process of language learning. Another possible reason for better performance of bilinguals in learning additional languages is their higher levels of metacognitive awareness (Afsharrad \& Sadeghi Benis; 2017; Keshavarz \& Ghamoushi, 2014)

To throw light on how bilingualism affects learning subsequent language(s), many scholars have compared bilinguals and monolinguals in different parts of the world (especially Europe, Canada, and the United States). These studies have compared bilinguals and monolinguals in L3 general proficiency (Muºz, 2000; Sanders \& Meijers, 1995), communicative sensitivity (Oskaar, 1990), pragmatic production and metapragmatic awareness (Safont Jorda, 2003), phonetic discrimination (Enomoto, 1994), lexical/syntactic learning (Klein, 1995), and writing (Sagasta Errasti, 2003).

Iranian scholars have also been interested in investigating differences between monolinguals and bilinguals in additional language learning. They have investigated different areas of L3 including socioaffective strategies in writing (Poorebrahim, Sattarpour, \& Fakher Ajabshir, 2019) reading comprehension and reading strategies (Afsharrad \& Sadeghi Benis, 2017; Keshavarz \& Ghamoushi, 2014; Modirkhamene, 2006), vocabulary learning (Kassaian \& Esmae'li, 2011; Keikhaie, Khoshkhoonejad, Mansoorzadeh, \& Panahandeh, 2015; Keshavarz \& Astaneh, 2004; Zare \& Davoudi Mobarakeh, 2013; Zarghami \& Bagheri, 2014; Zargosh, Karbalaei, \& Afraz, 2013), pragmatic awareness (Rahimi Domakani, Hashemian \& Mansoori, 2013), grammar (Merrikhi, 2012; Moghtadi, Koosha, \& Lotfi, 2015; Yeganeh, Ghoreyshi, \& Darabi, 2013).

Although there has recently been a growing trend on research on bilingualism, the number of studies in different areas is limited and the findings are not conclusive enough. Consequently, it is not safe to use such findings for the purpose of decision making. The following is a brief review of some L3 studies with contradictory findings:

Most of the studies carried out on L3 in Iran have investigated vocabulary learning from different angles. Zargosh, Karbalaei, and Afraz (2013) compared 74 Arab-Fars bilinguals and 92 Fars monolinguals. They found that bilinguals were better than monolinguals in learning vocabulary. This diverges from the findings of Zarghami and Bagheri (2014) who compared 35 Turk-Fars female bilinguals with 35 of their Fars monolingual counterparts. They found no significant difference between bilinguals and monolinguals in their vocabulary achievement.

Keshavarz and Astaneh (2004) compared performances of two bilingual groups (one TurkFars and the other Armenian-Fars) with that of a monolingual Fars group in vocabulary production ability. Their findings showed that bilinguals performed better than monolinguals. In a similar vein, Zare and Davoudi Mobarakeh (2013), who compared 50 Arab-Fars high school male bilinguals with 50 Fars monolinguals, found that bilinguals did better than monolinguals in general and in vocabulary production. However, there was no difference between the two groups in vocabulary recognition. In a similar study, 80 Baluch-Fars bilinguals were compared with 80 Fars monolinguals (Keikhaie, Khoshkhoonejad, Mansoorzadeh, \& Panahandeh, 2015). The results of this study deviated from those of the previouslymentioned studies; bilinguals did better than monolinguals just in recognition but not production of vocabulary.

After research on the effect of bilingualism on vocabulary learning, most L3 studies in Iran have examined reading skill and its relation to reading strategies. The findings of studies on reading seem to be more consistent than those on vocabulary. In a longitudinal survey, Modirkhamene (2006) compared reading achievement of 42 Fars monolinguals and 56 Turk-Fars bilinguals in three phases. The results of her study revealed better performance of bilinguals in all phases. Keshavarz and Ghamoushi (2014) compared 100 Turk-Fars bilinguals with 100 Fars monolinguals in terms of metacognitive reading strategy awareness. Their results showed that bilinguals were more aware of total reading strategies (supportive, global, and problem-solving strategies). Moreover, bilinguals reported to use more of global strategies than monolinguals. However, in the other two strategies, i.e. supportive and problem-solving strategies, there was no significant difference between the two groups. In a similar study, Afsharrad and Sadeghi Benis (2017) compared 50 Turk-Fars bilinguals with 36 Fars monolinguals in terms of cognitive, metacognitive, and total strategy use as well as reading comprehension performance. Their findings revealed superiority of bilinguals over monolinguals in metacognitive strategy use and reading comprehension. However, the two groups were not different in terms of cognitive and total strategy use. Unlike the findings of these studies, those of Ghabanchi (2011) did not exhibit any significant difference between monolinguals, bilinguals, and trilinguals in reading comprehension.

Considering grammar, Yeganeh, Ghoreyshi, and Darabi (2013) examined the effect of bilingualism on learning negative and placement adverbs. They did not find a significant difference between monolinguals and bilinguals, neither did Ghabanchi (2011). He compared monolinguals, bilinguals, and trilinguals, who were preparing for TOEFL, in grammar, listening comprehension, and reading comprehension. He found no significant difference between the three groups in any of the 
tested areas. This is against the findings of Merrikhi (2012). She compared Fars monolinguals, Armenian-Fars bilinguals, and Turk-Fars bilinguals. The results of her study revealed an advantage for bilinguals. Moreover, Armenians, who learnt their languages both academically and orally, were more successful than Turk learners, who learnt their L1 only orally. Similarly, Moghtadi, Koosha, and Lotfi, (2015) found a significant difference between monolinguals and bilinguals in both comprehension and production of relative clauses in favor of bilinguals. They investigated differences between Fars monolinguals and Turk-Fars bilinguals.

As seen above, research on L3 has not only produced inconsistent results but also devoted insufficient attention to some areas. According to Schalley, Eisenchlas, Guilllemin, (2016), little attention has been directed to the writing skill of multilinguals. One study that has examined multilingual learners' writing skill was conducted by Sagasta Errasti (2003) in Basque Country. She compared two groups of Spanish/Basque bilinguals. The medium of instruction for both groups was Basque (the minority language); Spanish (the majority language) and English (foreign language) were introduced as school subjects. One of the groups (maintenance) spoke Basque at home and the other group (immersion) spoke mainly Spanish out of school curriculum. The findings of her study suggested that the maintenance group produced better compositions than the immersion group. She concluded that using the minority language as the medium of instruction and also in social contexts is of help to L3 learning.

To the best of our knowledge, in the context of Iran, there is only one study (Modirkhamene, 2011) which has examined multilingual learners' writing skill. Based on the results of her study, bilinguals ${ }^{1}$ were proved to be significantly better English writers than their monolingual counterparts. She concluded that "writing skills and strategies and even concepts readily developed in the previous languages are accessible through the target language" (Modirkhamene, 2011, p. 132).

The current study takes a totally different view from those of Sagasta Errasti (2003) and Modirkhamene (2011). Sagasta Errasti (2003) examined the effect of using a minority language as the medium of instruction on L3 writing and Modirkhamene (2011) examined differences between bilinguals and monolinguals from a crosslinguistic-influence point of view while this study tries to focus on general effects of bilingualism on writing. The bilingual participants of this study have not learned their L1, Turkish, academically and are not familiar with its written system. Hence, there is no literacy transfer from L1 to L3. Moreover, monolinguals' L1 and bilinguals' L2 is the same (Farsi). Therefore, logically, if there is anything to be transferred from Farsi to English, most likely it occurs for both groups. This brings about a good situation to investigate indirect effects of bilingualism on L3 writing rather than direct literacy transfer.

In addition to the limited number of L3 studies and mixed results of these studies, there is another factor which demonstrates the need for more L3 research. Even if there were enough studies on bilingualism and the findings were conclusive, considering diversity in L3 studies (Cenoz, 2003), the results of studies conducted in one context and on one language could not be safely generalized to other contexts in which other languages are spoken. In other words, the findings of the aforementioned studies may not be applicable to all EFL settings due to differences in the combination of variables in each context (e.g., gender, level of proficiency, background languages, etc.). This underlines the need for more research on bilingualism (and especially on bilinguals' writing skill) from different points of view.

This study is an attempt to address the aforementioned problems and fill the existing gap in the literature by providing answers to the following research questions:

1. To what extent are monolingual Fars and bilingual Turk-Fars EFL learners different in English writing performance?

2. To what extent are monolingual Fars and bilingual Turk-Fars EFL learners different in their performance of English writing components (content, organization, discourse, syntax vocabulary, and mechanics)?

3. What are common differences between monolingual Fars and bilingual Turk-Fars EFL students in their use of language or combination of languages while thinking to write?

\section{METHOD \\ Participants}

A total of 109 university students participated in this study. The participants were juniors and their major was Teaching English as a Foreign Language (TEFL). They consisted of 57 monolingual Fars (Persian) and 52 bilingual Turk-Fars (TurkishPersian) females aged 18-22. For data collection through think-aloud procedure, from among those who agreed to think aloud 10 participants were randomly selected out of each group. The participants of the study had been learning English in an $\mathrm{EFL}^{2}$ context and their language learning experience was confined to the classroom. Before entering university, all participants had been taught through the same curriculum in the mainstream schools. In this curriculum, the medium of instruction is Farsi and English is introduced in grade 7 as a school subject. In each grade an average 
of about 3 hours a week is dedicated to English. The focus of the English courses is mainly on reading, grammar, vocabulary, and writing at sentence level.

In addition to mainstream high schools, attending in which is obligatory for all teenagers and English is only one of the subjects being taught, there are many private language schools in Iran, which offer specialized language teaching courses and are optional to attend. These schools are very active in teaching English and are becoming increasingly popular since they adopt a communicative approach to English language teaching/learning. In order to make sure that the participants of the study were similar in terms of exposure to English language, only those who reported to have attended private English classes for six months or less were chosen and the data for those who didn't meet this criterion were not included in the analyses.

Due to similarities in the syllabi of TEFL major at different universities, the participants also had similar experience of academic English language learning. At the onset of this study, all participants had already passed some courses on general English (including one writing course).

The bilingual participants of the study were from Tabriz, a city in northwest of Iran, where people speak Azeri Turkic (simply referred to as Turkish in this study) as their L1. It is worth mentioning that the Turkish spoken by the bilinguals of the study is slightly different from the language spoken in Turkey. The monolingual participants were from Isfahan where people mainly speak Farsi. However, since, due to such factors as mobility and migration, it is not adequate to consider place of living as the sole basis of being bilingual or monolingual, other factors were taken into account. In the background questionnaire which was used as one of the instruments for data collection, the participants were asked to determine the language(s) they actively used at home, university, and society and also with parents, friends, and peers. The final decision on the linguality status of the participants was made based on the results of the background questionnaire. That is, those who used both Farsi and Turkish for communication purposes were considered as bilinguals.

The bilingual participants of the study had learnt spoken Turkish as their native language in natural settings. They had started learning both spoken and written Farsi as their L2 in the first year of primary school. Moreover, they had been learning English as their L3 since they started secondary school at the age of twelve. On the other hand, the monolingual participants knew only one language, Farsi. They had a good command of spoken Farsi before going to school. Therefore, they learnt only written Farsi in the first grade of primary school. The monolingual participants have been learning English as their L2.

\section{Instruments}

Three instruments were used to collect data for this study: a background questionnaire, a writing task, and think-aloud procedure. The questionnaire provided the researcher with such data as age, gender, (number of) background language(s), age/context of learning L2, and language(s) spoken at home and school.

The writing performance of the participants was assessed through a writing task. The participants were asked to write a passage of about 250 words about the topic of 'social networking applications and websites: benefits and disadvantages'. This topic was chosen on the grounds that such applications are very popular nowadays and are used by many people. Hence, students are familiar with their advantages and disadvantages.

Before the study, the writing prompt was pilottested with a sample of 30 students. The purpose of pilot-testing was to make sure that the topic was appealing enough to the participants.

Moreover, the time limit (40 minutes) for the participants to complete the task was determined. In addition, the scoring scheme which was employed to mark the participants' compositions was tested in this stage.

In order to make sure that the scoring system could be used by different raters to mark the compositions consistently, inter-rater reliability was calculated. The compositions of the participants who took part in the pilot-testing were graded by the two researchers based on the writing scheme. The results of the scores from the two raters were submitted to Statistical Package for Social Sciences (SPSS, version 24). Pearson correlation was used to calculate interrater reliability. The results of the analysis revealed an intra-class correlation of .80, which is a large correlation, according to Cohen (1988).

The scoring scheme used to mark the compositions was developed based on the suggestions of Brown (2001) and Nunan (1999). The total score for writing was 100 . In this scoring system, six main components of writing were taken into account (points dedicated to each component and subcomponent are provided in parentheses). The first component was content (24), which had four subcomponents of thesis statement (6), related ideas (6), development through personal experience and illustration (6), and discussing all aspects of the topic (6). The second component, organization (20), included effectiveness of introduction (5), effectiveness of conclusion (5), separate paragraphs (5), and appropriate length (5). The third component, discourse (20), had the following subcategories: topic sentence (4), paragraph unity and coherence (8), and cohesion (8). Syntax (12), the fourth component, included clause structure and parallel structure (1), word order (1), tense and 
voice (1), subject-verb agreement (1), verb form (1), singular/plural nouns (count non-count) (1), modifying (1), part of speech (1), prepositions (1), articles (1), pronouns (1), and possessive form (1). The fifth component, vocabulary (12), had three sub-categories of effective word choice (4), appropriate register (4), and collocation (4). Finally, mechanics (12) was tested based on the following factors: spelling (3), punctuation (3), neatness and appearance (3), and capitalization (3).

\section{Procedure}

After getting permissions for collecting data, one of the researchers attended the universities at the agreed time. Collecting data from each class took about 50 minutes. At the onset of the session the participants were briefed about the purpose of the study for which data were going to be collected. They were assured that the data would be confidential and would be used only for research purposes. Then, instructions were given on how they should complete the task. They were also encouraged to ask questions in case there were any ambiguities. Then, the papers for writing were distributed and the participants were asked to write a text based on the given instructions (two sample compositions are provided in Appendix A). After that, they completed the background information questionnaire in about 10 minutes. The same procedure was followed for the think-aloud participants. The only difference was that the voice of this latter group was recorded for further analysis.

After data were collected, the compositions were marked using the scoring system described in the previous section. Finally, the data were submitted to SPSS (version 24) for analysis. Think aloud protocols were also transcribed. Since the purpose of think-aloud procedure was only examining the proportion of languages used, we did not stick to a pre-established set of rules on how to transcribe. The results of data analysis are reported and discussed in the next section.

\section{FINDINGS AND DISCUSSION}

Descriptive statistics for total writing and different components of writing are presented in Table 1.

Table 1

Means and Standard Deviations for Total Writing and Components of Writing

\begin{tabular}{lllccc}
\hline \multirow{2}{*}{ Total } & Linguality & $\boldsymbol{N}$ & Mean & Std. Deviation & Std. Error Mean \\
& Monolingual & 57 & 63.08 & 11.06 & 1.47 \\
Content & Bilingual & 52 & 68.51 & 9.42 & 1.31 \\
& Monolingual & 57 & 15.53 & 4.00 & .53 \\
Organization & Bilingual & 52 & 15.60 & 4.36 & .60 \\
& Monolingual & 57 & 5.86 & 4.77 & .63 \\
Discourse & Bilingual & 52 & 9.21 & 3.96 & .55 \\
& Monolingual & 57 & 12.84 & 2.71 & .36 \\
Syntax & Bilingual & 52 & 13.56 & 2.73 & .38 \\
& Monolingual & 57 & 9.97 & 1.00 & .13 \\
Vocabulary & Bilingual & 52 & 9.71 & 1.15 & .16 \\
& Monolingual & 57 & 10.89 & 1.13 & .15 \\
Mechanics & Bilingual & 52 & 10.62 & .91 & .13 \\
& Monolingual & 57 & 7.98 & 1.77 & .23 \\
\hline
\end{tabular}

As the first step to compare the groups, the data were examined for the underlying assumptions of parametric tests. The analyses revealed that the variances were equal but the data were not normally distributed. Hence, instead of $\mathrm{t}$ test, based on Larson-Hall (2010), a series of nonparametric Mann Whitney $U$ tests were employed to compare the groups in total writing performance and different components of writing. In Mann Whitney U test, mean ranks and medians are used to compare the groups. These statistics are presented in Table 2.

The results of the Mann Whitney $U$ tests are reported and discussed in the following sections.

\section{Total writing}

All bilinguals (100\%) earned a passing score (at least 50 out of 100) for their compositions whereas
$94.7 \%$ of monolinguals did so. Bilinguals' mean score in writing was 68.51 and monolinguals' was 63.08. The results of Mann Whitney U test revealed a significant difference in writing performance between monolinguals $(\mathrm{Mdn}=61)$ and bilinguals $(\mathrm{Mdn}=67.5), \mathrm{U}=971.50, \mathrm{Z}=-3.098, \mathrm{p}=0.002, \mathrm{r}=$ 0.30 .

Bilinguals of this study had a significantly better performance than monolinguals in total writing performance. This provides evidence in favor of indirect effect of bilingualism on L3 writing. Previous research (e.g. Modirkhamene, 2011) has shown that biliteracy fosters the process of L3 writing (through direct transfer of skills), especially when learners' previously known language(s) and target language(s) are similar 
(Bialystok, Luk, \& Kwan, 2005). The fact that bilinguals of this study were not literate in their L1 and yet performed better than monolinguals in English as L3 writing supports the idea that being bilingual without necessarily being biliterate is of help to the process of learning writing in additional languages.

In this study, bilinguals were not literate in their L1 (Turkish). Thus, they could not have benefited from transfer of writing skills from their previous languages more than monolinguals could. That is, bilinguals did not have the benefit of transferring L1 (Turkish) writing knowledge to L3 (English) writing situations and if there was anything that could be transferred from L2 (Farsi) to L3 (English), as far as writing is considered, both groups enjoyed that benefit. Hence, there must have been aspects of bilingualism other than biliteracy from which bilinguals gained advantage while writing in English as their L3.

Table 2

Medians, Mean Ranks, and Sum of Ranks for Total Writing and Components of Writing

\begin{tabular}{lllccc}
\hline \multirow{2}{*}{ Total } & Linguality & $\boldsymbol{N}$ & Median & Mean Rank & Sum of Ranks \\
& Monolingual & 57 & 61 & 46.04 & 2624.50 \\
Content & Bilingual & 52 & 67.5 & 64.82 & 3370.50 \\
& Monolingual & 57 & 16 & 55.01 & 3135.50 \\
\multirow{5}{*}{ Organization } & Bilingual & 52 & 15 & 54.99 & 2859.50 \\
& Monolingual & 57 & 4 & 42.08 & 2398.50 \\
& Bilingual & 52 & 10 & 69.16 & 3596.50 \\
\multirow{3}{*}{ Syntax } & Monolingual & 57 & 13 & 51.55 & 2938.50 \\
\multirow{2}{*}{ Vocabulary } & Bilingual & 52 & 13 & 58.78 & 3056.50 \\
\multirow{4}{*}{ Mechanics } & Monolingual & 57 & 10 & 57.85 & 3297.50 \\
& Bilingual & 52 & 10 & 51.88 & 2697.50 \\
& Monolingual & 57 & 11 & 59.91 & 3415.00 \\
& Bilingual & 52 & 11 & 49.62 & 2580.00 \\
& Monolingual & 57 & 8 & 39.25 & 2237.00 \\
\hline
\end{tabular}

Better performance of bilinguals over monolinguals in writing can also be the result of how each group learnt their first written language, Farsi. Writing is usually learnt in formal settings. Thus, bilinguals, who started learning spoken and written Farsi simultaneously and in formal classrooms, have paid more careful attention to language rules and developed an awareness towards writing rules. On the other hand, monolinguals, who acquired Farsi in natural settings, may have devoted less attention to formal rules of written Farsi and applied their knowledge of spoken Farsi to writing in Farsi. Both groups have transferred their experience of dealing with writing tasks in Farsi to accomplish English writing tasks. In other words, bilinguals might have been more aware that certain rules, which are sometimes different from the rules of speaking, should be followed in writing.

The findings of this study supports those of Modirkhamene (2011), who found a significant difference between bilinguals and monolinguals in writing. She related better performance of bilinguals to their experience in language learning. According to her, bilinguals, who have already accomplished the complex task of learning two languages, have developed a competence to tackle the task of learning an L3. This competence makes the process of learning additional languages easier for them. Moreover, based on her, such factors as using the knowledge of two languages, effective use of cognitive strategies, and active use of both languages in different contexts have a facilitative role in the process of L3 learning for bilinguals.
Hence, apart from how bilinguals and monolinguals of this study had learnt writing for the first time, other factors might also have resulted in the difference between the two groups.

\section{Content}

In content, bilinguals had better performance than monolinguals; $86.5 \%$ of bilinguals and $80.7 \%$ of monolinguals got a passing score (at least 12 out of 24). Bilinguals' mean score $(M=15.60)$ in content was slightly higher than that of monolinguals $(\mathrm{M}=$ 15.53). However, the results of the Mann Whitney $U$ test which was employed to compare the groups in the content of the their writing revealed that the difference between bilinguals $(\mathrm{Mdn}=15)$ and monolinguals $(\mathrm{Mdn}=16)$ was not significant, $\mathrm{U}=$ 1481.50, $\mathrm{Z}=-.003, \mathrm{p}=.998, \mathrm{r}=0.00$.

The lack of a meaningful difference between the content of the two groups' compositions may be accounted for by the context of language learning. Bilinguals and monolinguals of this study have learnt their languages in the same culture and context (Iran). Hence, they are both likely to have similar world knowledge and similar ideas about general topics such as advantages and disadvantages of social networking applications. The difference between bilinguals and monolinguals might have been bigger if they had learnt their languages in different contexts and cultures.

\section{Organization}

In organization, $51.9 \%$ of bilinguals and only $19.3 \%$ of monolinguals achieved passing scores (at least 10 
out of 20). Moreover, both groups' mean scores were below the passing score; bilinguals' mean score was 9.21 and monolinguals' was 5.86. In other words, Turk-Fars EFL learners did better than their Fars counterparts in the organization of their compositions, although both groups had low scores. The results of Mann Whitney $\mathrm{U}$ test, $\mathrm{U}=745.50, \mathrm{Z}$ $=-4.489, \mathrm{p}=0.000, \mathrm{r}=0.43$, revealed that the difference between bilinguals $(\operatorname{Mdn}=10)$ and monolinguals ( $\mathrm{Mdn}=4)$ was significant.

Neither monolinguals nor bilinguals had an acceptable organization in their writing. Their weakness in organization is likely to have resulted from inappropriate training in both English and Farsi writing and also from lack of training writing in Turkish for bilinguals. Based on Naghdipour (2016), Iranian EFL learners' writing performance is not at a satisfactory level. This, among other plausible reasons, is because English writing is still being introduced and taught through product approach and enough attention is not paid to the process of writing (Birjandi \& Malmir, 2009; Naghdipour, 2016). Moreover, since the bilingual participants had learnt their L1 (Turkish) only orally in natural settings, they did not learn anything related to writing in their L1. In other words, they did not receive schooling in Turkish and their academic language was Farsi, in which none of the participants had been trained well to write. Considering teaching writing in Farsi, in typical composition classes students used to be given a topic to write about without being trained on how they should write ${ }^{3}$. Therefore, none of the groups had good organizational knowledge to draw on while writing in English.

Having received the same training in writing and yet earning significantly different scores in organization indicates that there are other variables than training that have influenced the writing ability of the participants. One of these variables is the number of background languages. Bilinguality might have helped bilinguals better organize ideas into meaningful paragraphs. Since bilinguals practice organizing ideas in two languages, they have better organizational knowledge and do better than monolinguals in organizing their ideas in writing.

\section{Discourse}

With regard to discourse, more of bilinguals (96.2\%) than monolinguals $(93 \%)$ had a passing score (at least 10 out of 20). Bilinguals' mean (13.56) was also slightly higher than monolinguals' (12.84); however, both groups had the same median $(\mathrm{Mdn}=13)$. Based on the results of Mann Whitney $\mathrm{U}$ test, $\mathrm{U}=1285.50, \mathrm{Z}=-1.202, \mathrm{p}=0.229, \mathrm{r}=0.12$, the difference between the two groups was not significant. Therefore, it can be concluded that bilingualism does not significantly affect discoursal knowledge of bilingual learners of English as L3.
Both monolinguals and bilinguals of this study had reasonable knowledge of topic sentence. However, they still had trouble observing coherence and cohesion in their writing although many of them could get passing scores in discourse.

\section{Syntax}

The participants had many problems related to parallel structure and clause structure, subject verb agreement, article, and preposition. Some of their problems are as follows (mistakes are in italic and missing words in [brackets]):

- $\quad$ 'in telegram you can make [a] channel and exchange of lots of information.'

- $\quad$ 'the channel that are for English ...'

- ' '...on the most of the smart phones ...'

- 'That they don't know the person who he or she is chatting with him or her.'

- 'The advantages of the using social networking are the easily using and make the communication easy...'

Considering the grammatical accuracy of the compositions, all bilinguals $(\mathrm{M}=9.71)$ and all monolinguals $(\mathrm{M}=9.97)$ achieved a passing score (at least 6 out of 12). Both bilinguals and monolinguals had the same median $(\mathrm{Mdn}=10)$ and the difference between them was not significant, $\mathrm{U}$ $=1319.50, \mathrm{Z}=-0.998, \mathrm{p}=0.318, \mathrm{r}=0.10$.

Based on the results, it can be stated that bilingualism does not have a significant effect on learners' grammatical accuracy of compositions. This is in line with the findings of Yeganeh, Ghoreyshi, and Darabi (2013). They compared monolinguals and bilinguals' performance in learning negative and placement adverb structures and did not find any difference between the two groups. Similarly, Ghabanchi (2011) found that bilinguals and monolinguals were not statistically different in learning English grammar.

On the other hand, the findings run counter to those of a number of other studies which found significant differences between monolinguals and bilinguals in English grammar. Merrikhi (2012), for example, found that bilinguals, especially biliterate bilinguals, were better in learning English grammar than monolinguals. Similarly, Moghtadi, Koosha, and Lotfi, (2015), who compared bilinguals and monolinguals in comprehension and production of relative clauses, found that bilinguals performed better than monolinguals.

\section{Vocabulary}

The difference between bilinguals and monolinguals in terms of vocabulary use in writing was not big. All bilinguals $(\mathrm{M}=10.62)$ and all monolinguals ( $\mathrm{M}$ $=10.89$ ) got a passing score (at least 6 out of 12). Having the same median $(\operatorname{Mdn}=11)$, as the results of Mann Whitney U test revealed, $\mathrm{U}=1202, \mathrm{Z}=$ - 
1.733, $\mathrm{p}=0.076, \mathrm{r}=0.17$, the two groups were not significantly different in their use of vocabulary.

Based on the results, it can be concluded that bilingualism does not improve vocabulary production ability of bilinguals in English as L3. This is against the findings of Keshavarz and Astaneh (2004). They found that bilinguals were better than monolinguals in vocabulary production. Similarly, Zare and Davoudi Mobarakeh (2013) found a significant difference in favor of bilinguals in vocabulary production but not in vocabulary recognition. In contrast, Keikhaie, Khoshkhoonejad, Mansoorzadeh, and Panahandeh (2015) found that bilinguals were better than monolinguals in vocabulary recognition but not in vocabulary production.

The findings related to vocabulary diverge from those of some other studies, too. Zargosh, Karbalaei, and Afraz (2013), for example, found that bilinguals were significantly better than monolinguals in learning English vocabulary. Bilinguals were also reported to have a wider breadth of vocabulary knowledge than monolinguals. (Kassaian \& Esmae'li, 2011).

The inconsistency in the findings of L3 studies on vocabulary may be related to a range of factors such as type of bilingualism (e.g. balanced vs. dominant bilingualism), threshold level, background languages, and age/sex of the participants. The inconclusive findings may also be explained by the instruments used in different studies to elicit data.

\section{Mechanics}

All bilinguals $(\mathrm{M}=9.83)$ obtained a passing score (6 out of 12) for mechanics of writing. On the other hand, $93 \%$ of monolinguals $(\mathrm{M}=7.98)$ earned a passing score for this component of writing. The results of Mann Whitney $\mathrm{U}$ test, $\mathrm{U}=584, \mathrm{Z}=$ $5.544, \mathrm{p}=0.000, \mathrm{r}=0.53$, demonstrated that bilinguals' median $(\mathrm{Mdn}=10)$ in mechanics was statistically higher than monolinguals' $(\mathrm{Mdn}=8)$.

Better performance of bilinguals, as compared to monolinguals, in mechanics might be explained by how each group learnt writing skill for the first time. In grade 1 of school, monolinguals learnt only the written form of the language they already knew (Farsi) but bilinguals started learning a totally new language. In Iranian settings English books taught at mainstream schools follow a structural syllabus. Such language learning settings requires more attention on the part of learners to the formal rules of language. Therefore, since they knew no Farsi at the beginning of their first year of schooling, the bilinguals might have had to pay more attention to the rules of language, including rules of mechanics. On the other hand, monolinguals, who had acquired Farsi in natural settings, may have paid less attention to the formal rules of written Farsi, especially mechanics. In fact, their already knowing most of the rules unconsciously might have resulted in their becoming less sensitive towards learning other rules including rules of mechanics. However, further qualitative research is needed to examine the accuracy of this speculation and also finding other potential reasons for the difference between the two groups.

To find the proportion of languages the participants used while thinking to write, the answer to the third research question, the number of words they said during their think-aloud were counted. The results are presented in Table 3.

Table 3

Percent of Words Used by Different Groups in Think-Aloud Process

\begin{tabular}{lccc}
\hline Group & English & $\begin{array}{c}\text { Language } \\
\text { Farsi }\end{array}$ & Turkish \\
\hline Bilingual & 48.4 & 42.6 & 9 \\
Monolingual & 56.2 & 43.8 & -- \\
\hline
\end{tabular}

It is clear that both groups have used more of the target language, English, while thinking to write an argumentative text in target language. The difference between the two groups, however, is that bilinguals have used a minimal use $(9 \%)$ of their mother tongue while monolinguals have thought in their L1 about half of the time (43.8\%). In other words, the percent of words the two groups produced in Farsi is very close but this language, Farsi, is bilinguals' L2 and monolinguals' L1. The reason for this can be related to status, available modalities, and proficiency level of the languages they know. That is, bilinguals thought more in their L2 (Farsi) than L1 (Turkish) in the process of writing in an L3 (English) perhaps because they were not proficient enough in English to do all the thinking in L3 (just like monolinguals weren't). Moreover, the fact that bilinguals L1 doesn't have written modality and they have learnt writing in L2 might explain why they used Farsi (which is the language of instruction, is the formal language of the country, and has written form) more than Turkish while writing in English.

Based on the results of the study a number of implications can be drawn. The most important implication of this study is for policymakers. The policy in Iran is that the same books, including English books, are used in all mainstream schools across Iran. For example, students in grade seven study the same English book at school regardless of where in Iran they are living and what their background languages and specific needs are. Hence, the most crucial decisions about change in educational materials need to be made by policy makers. They can take the findings of this study into account and develop bilingual systems of education for bilingual regions. Bilinguals of this study were found to have benefited from some advantages of bilingualism. However, their being bilingual could have been of more help if their L1 had written form and was actively used in their schools. Research has 
shown that biliterate bilinguals benefit from their being bilingual more than monoliterate bilinguals do (Keshavarz \& Astaneh, 2004; Merrikhi, 2012; Ng, 2013). Moreover, active use of minority language as the medium of instruction has been proved to be of help to the process of learning subsequent languages (Sagasta Errasti, 2003). Therefore, it is a good idea to consider including localized programs in which the use of both spoken and written forms of minority languages in educational systems is encouraged.

Currently, for all school subjects the same materials (exclusively in Farsi) are being used in all parts of Iran for students from all ethnic groups, no matter what their L1 is and whether they are ready to learn written Farsi or not. About half of Iranians speak languages other than Farsi as their L1 (Shaffer, 2002). Most of them get familiar with both spoken and written Farsi simultaneously when they start going to school at the age of seven. These students are not prepared enough to learn written Farsi since they have not yet learnt spoken Farsi. More importantly, how can we expect these students to have good performance in their school subjects while they are not familiar with the medium of instruction? Research has shown that Turk-Fars bilingual first graders have more problems, especially in listening and perception of Farsi (Osareh, 2008). This reveals the importance of education in L1 in the first years of schooling.

The results of this study revealed differences between Fars monolinguals and Turk-Fars bilinguals in organization and mechanics of writing and also in total writing performance. This cannot be safely generalized to contexts in which languages other than Farsi and Turkish are used. In other words, benefits of bilingualism may be different for bilinguals with different background languages. By focusing on and comparing bilinguals of different background languages with each other and also with monolinguals, future research can not only find differences between bilinguals and monolinguals in general but also shed light on the differential effects of various languages on the process of learning additional languages. In this way, bilinguals with different background languages are more likely to be provided with methods of teaching and learning which are geared towards their potentials.

Another point that can be captured by future studies is considering differences between monolinguals and bilinguals from a qualitative point of view, which was beyond the scope of this study. In the current study bilinguals and monolinguals were compared only from a quantitative perspective. In-depth investigation of differences between monolinguals and bilinguals through qualitative studies and mixed research designs will provide us with a better understanding of how we can benefit from the advantages of bilingualism in the process of learning subsequent languages.

\section{CONCLUSION}

In this study, the effect of bilingualism on L3 learning was investigated by examining differences between monolinguals and bilinguals in learning English writing. In an effort to offer evidence to the field of L3 learning from an underrepresented context, this study was conducted in Iran. A lot of languages are spoken in Iran. However, only a few of them have a writing system. Moreover, the writing system of Farsi language is totally different from those investigated in many other studies; Farsi is written from right to left, unlike most languages which have a left-to-right writing system. This provides a good context to investigate how being able to speak two languages (but to write in only one of them) can be of help to L3 writing. Based on the findings of this study, monoliterate bilinguals, as compared to monolinguals, significantly produce more organized texts, make fewer mistakes in mechanics of writing, and have better overall writing performance. However, this type of bilingualism does not differentiate between bilinguals and monolinguals in content, vocabulary, discourse, and syntax of their writing. Based on the findings of the study, it can be concluded that, apart from direct literacy transfer from previously known languages to target language, bilingualism is of help to L3 writing process indirectly. However, based on previous research, bilinguals can benefit more from their previous languages in the process of learning L3 if they are biliterate, too. By designing localized bilingual systems of education and recognizing the importance of using L1 in learning subsequent languages, policy makers can increase bilingual learners' potential so that bilinguals can enjoy maximized benefits of bilingualism. By doing so, they also respond to the call of learners and teachers, who feel that it is not only beneficial but essential to use L1 to facilitate learning other languages (Zohrabi, Yaghoubi-Notash, \& Khodadadi, 2014).

\section{REFERENCES}

Afsharrad, M. \& Sadeghi Benis, A. R. (2017). Differences between monolinguals and bilinguals/males and females in English reading comprehension and reading strategy use. International Journal of Bilingual Education and Bilingualism, 20(1), 34-51. https://doi.org/10.1080/13670050.2015.103723 8

Bangert-Drowns, R. L., Hurley, M. M., \& Wilkinson, B. (2004). The effects of schoolbased Writing-to-Learn interventions on academic achievement: A meta-analysis. Review of Educational Research, 74, 29-58. https://doi.org/10.3102\%2F003465430740010 29 
Bialystok, E., Luk, G., \& Kwan, E. (2005). Bilingualism, biliteracy, and learning to read: Interactions among languages and writing systems. Scientific Studies of Reading, 9, 4361. https://doi.org/10.1207/s1532799xssr0901_4

Birjandi, P., \& Malmir, A. (2009). The effect of task-based approach on the Iranian advanced EFL learners' narrative vs. expository writing. Iranian Journal of Applied Language Studies 1(2). 1-26. https://dx.doi.org/10.22111/ijals.2011.50

Brown, H. D. (2001). Teaching by principles: An introductive approach to language pedagogy Pearson.

Cenoz, J. (2003). The additive effect of bilingualism on third language acquisition: A review. International Journal of Bilingualism, 7(1), 71-87.

https://doi.org/10.1177\%2F136700690300700 10501

Cohen, J. (1988). Statistical power analysis for the behavioral sciences. Sage.

Enomoto, K. (1994). L2 perceptual acquisition: The effect of multilingual linguistic experience on the perception of a 'less novel' contrast. Edinburgh Working Papers in Applied Linguistics, 5, 15 -29.

Ghabanchi, Z. (2011). Trilingualism and Foreign Language Proficiency. World Journal of Education, 1(2): 181-190. https://doi.org/10.5430/wje.v1n2p181

Graham, S., \& Hebert, M. (2010). Writing to reading: Evidence for how writing can improve reading. Alliance for Excellence in Education.

Graham, S., \& Hebert, M. (2011). Writing-to-read: A meta-analysis of the impact of writing and writing instruction on reading. Harvard Educational Review, 81, 710-744. https://doi.org/10.17763/haer.81.4.t2k0m13756 113566

Graham, S., \& Perrin, D. (2007). Writing next: Effective strategies to improve writing of adolescent middle and high school. Alliance for Excellence in Education.

Graham, S., Gillespie, A., \& McKeown, D. (2013). Writing: Importance, development, and instruction. Reading and writing, 26(1), 1-15. https://doi.org/10.1007/s11145-012-9395-2

Herdina, P., \& Jessner, U. (2002). A dynamic model of multilingualism. Multilingual matters.

Kassaian, Z. \& Esmae'li, S. (2011). The effect of bilinguality on L3 breadth of vocabulary knowledge and word reading skill. Theory and Practice in Language Studies, 1(8), 966-974. https://doi.org/10.4304/tpls.1.8.966-974

Keikhaie, Y., Khoshkhoonejad, A., Mansoorzadeh, N., \& Panahandeh, E. (2015). Bilingualism and vocabulary learning: A comparison between
Baluchi and Persian EFL learners. Journal of Education and Learning, 9(3). 183-189. http://dx.doi.org/10.11591/edulearn.v9i3.1767

Keshavarz, M. H., \& Astaneh, H. (2004). The impact of bilinguality on the learning of English vocabulary as a foreign language (L3). International Journal of Bilingual Education and Bilingualism 7 (4): 295-302. https://doi.org/10.1080/13670050408667814

Keshavarz, M. H., \& Ghamoushi, M. (2014). A comparative study of metacognitive awareness of reading strategies among monolingual and bilingual Iranian EFL learners. Advances in Language and Literary Studies, 5(4), 25-32. https://doi.org/10.7575/aiac.alls.v.5n.4p.25

Klein, E. C. (1995). Second versus third language acquisition: Is there a different? Language Learning, 45, 419-465. https://doi.org/10.1111/j.14671770.1995.tb00448.x

Larson-Hall, J. (2010). A guide to doing statistics in second language research using SPSS. Routledge.

Merrikhi, P. (2012). The effect of bilingualism on Iranian pre-university students' English grammar proficiency. Theory and Practice in Language Studies, 2(2), 360-370. https://doi.org/10.4304/tpls.2.2.360-370

Modirkhamene, S. (2006). The reading achievement of third language versus second language learners of English in relation to the interdependence hypothesis. International Journal of Multilingualism, 3(4), 280-295. https://doi.org/10.2167/ijm043.0

Modirkhamene, S. (2011). Cross-linguistic transfer or target language proficiency: writing performance of trilinguals vs. bilinguals in relation to the interdependence hypothesis. Journal of English Language Teaching and Learning, 3(7), 115-143. https://elt.tabrizu.ac.ir/article_622.html

Moghtadi, L., Koosha, M., \& Lotfi. A. (2015). Learning of relative clauses by L3 learners of English. Applied Research on English Language, 4(1). 79-106. https://dx.doi.org/10.22108/are.2015.15493

$\mathrm{Mu}$ oz, C. (2000). Bilingualism and trilingualism in school students in Catalonia. In J. Cenoz \& U. Jessner (eds.), English in Europe: The acquisition of a third language (pp. 157-178). Multilingual Matters.

Naghdipour, B. (2016). English writing instruction in Iran: Implications for second language writing curriculum and pedagogy. Journal of Second Language Writing, 32, 81-87. https://doi.org/10.1016/j.jslw.2016.05.001

$\mathrm{Ng}$, E. (2013). Formulation processes and metacognition of monolingual, bilingual and biliterate writers: From thinking to writing in 
English and Chinese [Unpublished doctoral dissertation]. University of Sydney.

Nunan, D. (1999). Second language teaching and learning. Heinle \& Heinle Publishers.

Osareh, F. (2008). Investigation of language learning problems of first grade students in bilingual regions. Educational Sciences, 9, 42-60. Retrieved from http://www.noormags.ir/view/fa/articlepage/3 88060.

Oskaar, E. (1990). Language contact and culture contact: Towards an integrative approach in second language acquisition research. In $\mathrm{H}$. Dechert (ed.), Current trends in European second language acquisition research (230243). Multilingual Matters.

Poorebrahim, F., Sattarpour, S. \& Fakher Ajabshir, Z. (2019). Written text quality and socioaffective strategy use: Monolinguals versus bilinguals across different proficiency levels. The Journal of Asia TEFL, 16(4), 1069-1460. http://dx.doi.org/10.18823/asiatefl.2019.16.4.4. 1119

Rahimi Domakani, M., Hashemian, M., \& Mansoori, S. (2013). Pragmatic awareness of the request speech act in English as an additional language: Monolinguals or bilinguals?, Journal of Research in Applied Linguistics, 4(1), 88-110. http://rals.scu.ac.ir/article_10471.html

Safont Jorda, M. (2003). Metapragmatic awareness and pragmatic production of third language learners of English: A focus on request acts realizations. International Journal of Bilingualism, 7(1), 43-61. https://doi.org/10.1177\%2F136700690300700 10401

Sagasta Errasti, M. P. (2003). Acquiring writing skills in a third language: The positive effects of bilingualism. International Journal of Bilingualism, 7(1), 27-42. https://doi.org/10.1177\%2F136700690300700 10301

Sanders, M., \& Meijers, G. (1995). English as L3 in the elementary school. International Journal of
Applied Linguistics, 107, 59-78. https://doi.org/10.1075/itl.107-108.04san

Schalley, A. C., Eisenchlas, S. A. \& Guillemin, D. (2016). Multilingualism and literacy: Practices and effects. International Journal of Bilingual Education and Bilingualism, 19(2), 127-135. https://doi.org/10.1080/13670050.2015.103771 4

Shaffer, B. (2002). Borders and Brethren: Iran and the challenge of Azerbaijani identity. The MIT Press.

Yeganeh, M., Ghoreyshi, M., \& Darabi, R. (2013). The effect of explicit and implicit instruction on monolingual bilingual EFL learners and acquisition of 12 grammar. European Online Journal of Natural and Social Sciences, 2(2), 160-167. http://europeanscience.com/eojnss_proc/article/view/3603

Zare, M., \& Davoudi Mobarakeh, S. (2013). Effects of bilingualism on L3 vocabulary learning among Iranian EFL learners. GEMA Online Journal of Language Studies, 13(1), 127-138. http://ejournal.ukm.my/gema/article/view/2247

Zarghami, S., Bagheri, S. M. S. (2014). The impact of bilingualism on English vocabulary learning among middle school students. Journal of Studies in Learning and Teaching English, 2(5), 41-60.

http://jslte.iaushiraz.ac.ir/article_519011_e731 5c26600ad60bbc3a3715ef07c69a.pdf

Zargosh, M., Karbalaei, A., \& Afraz, S. (2013). The effect of thematic clustering on enhancing monolingual and bilingual EFL learners' vocabulary acquisition. European Online Journal of Natural and Social Sciences, 2(2), 109-121. https://dx.doi.org/10.22108/are.2017.21323

Zohrabi, M., Yaghoubi-Notash, M., \& Khodadadi, A. (2014). The facilitating role of Iranian learners' first language in learning English vocabulary. International Journal on Studies in English Language and Literature (IJSELL), 2 (8), 44-57. https://www.arcjournals.org/pdfs/ijsell/v2i8/7.pdf 


\section{APPENDIX}

Samples of Participants' marked compositions

\section{Figure A1}

Composition written by One of the Monolingual Participants

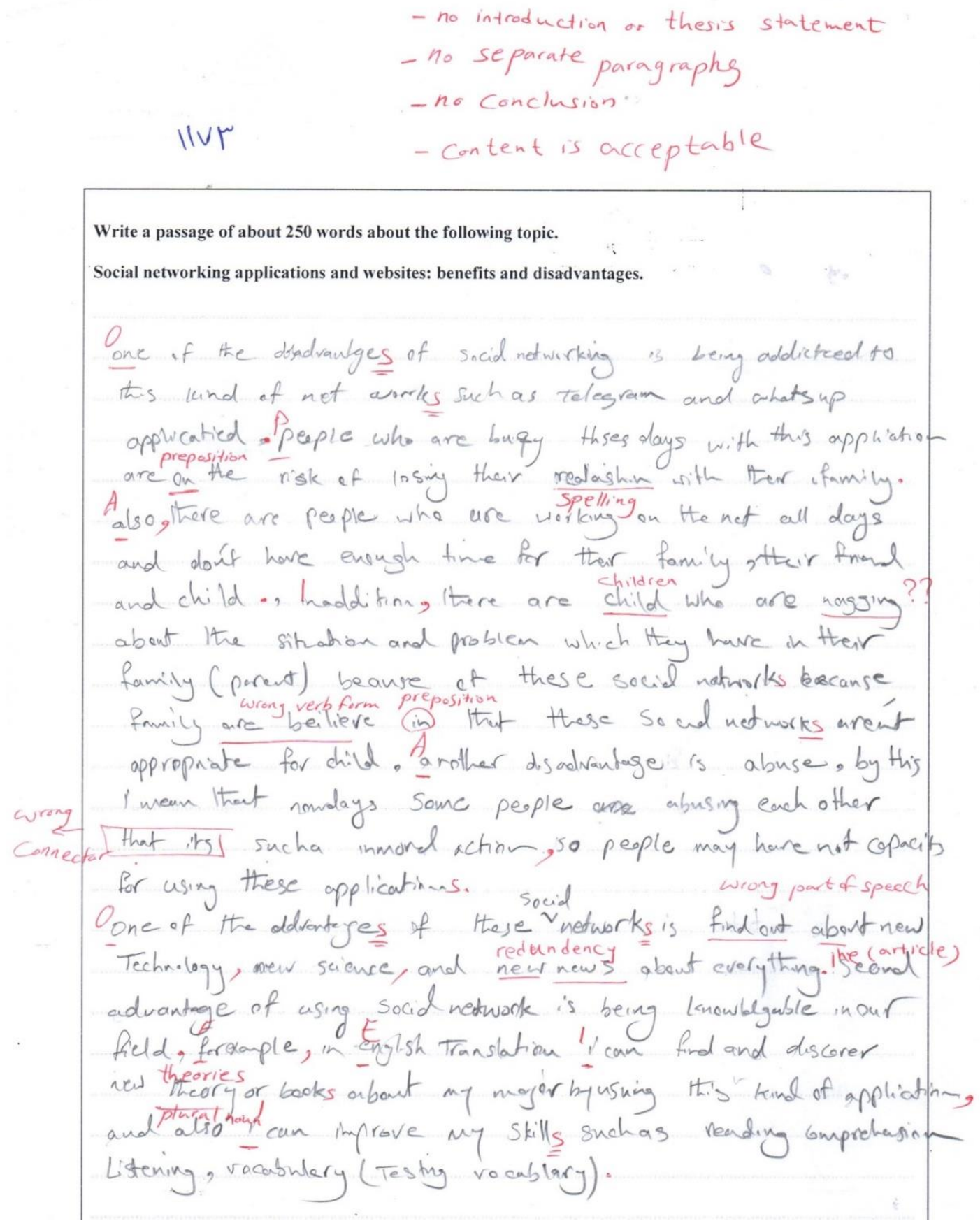


Figure A2

Composition Written by One of the Bilingual Participants

( $r$ IUO)

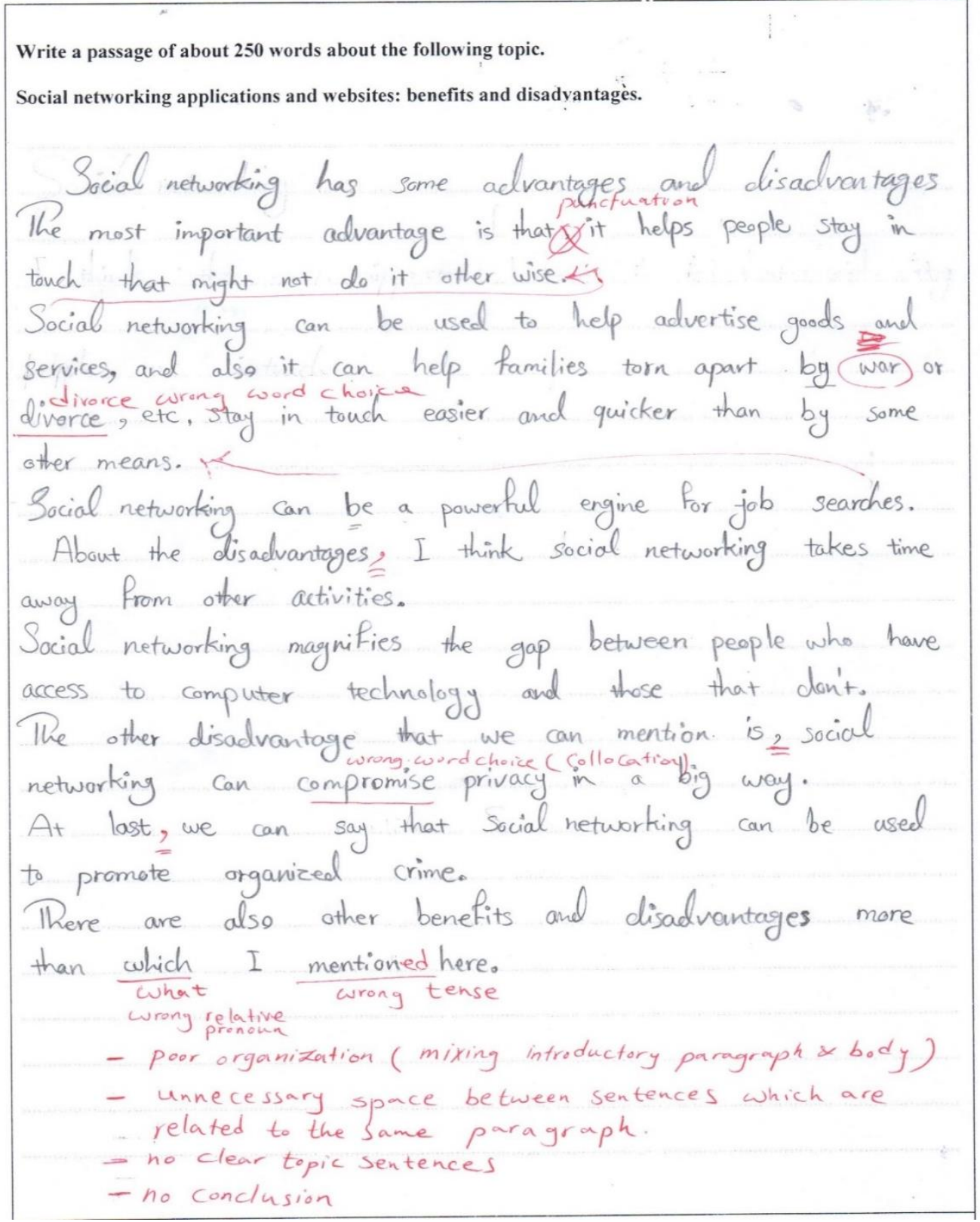

1 In Modirkhamene's (2011) study those who knew three languages of Turkish, Farsi, and English were considered as trilinguals only because of their good command of English language. In fact, they could have been considered as bilinguals who already knew Turkish and Farsi and were proficient learners of English as L3. Also, the other group could have been considered as Fars monolinguals who were proficient learners of English as L2. It seems that the superficial difference between the participants of her study and other studies reviewed here is only a matter of different terminology to refer to the same phenomenon. Therefore, Modirkhamene's (2011) can be grouped with the studies addressing the effect of bilingualism on L3 learning.

${ }^{2}$ In Iran English is a foreign language. That is, English is not an official/main medium of communication

${ }^{3}$ It is worth mentioning that major changes are being introduced to the educational system of Iran. These changes include updating both the curriculum and the course books. However, the participants of this study had graduated from high school before the changes were initiated. 